\title{
Analysis of single nucleotide polymorphisms in chronic beryllium disease
}

\author{
Björn C. Frye ${ }^{1}$ [0, Karoline I. Gaede ${ }^{2,11}$, Cesare Saltini ${ }^{3}$, Milton D. Rossman ${ }^{4}$, Dimitri S. Monos ${ }^{4}$, Ken D. Rosenman ${ }^{5}$, \\ Christine R. Schuler ${ }^{6}$, Ainsley Weston ${ }^{6}$, Ralf Wegner ${ }^{7}$, Rainer Noth ${ }^{8}$, Gernot Zissel ${ }^{1}$, Stefan Schreiber ${ }^{8}$, \\ Michael Nothnagel ${ }^{9,10}$ and Joachim Müller-Quernheim ${ }^{1 *}$
}

\begin{abstract}
Sarcoidosis and chronic beryllium disease (CBD) are phenocopies, however the latter one has a clear trigger factor that is beryllium exposure. This study analyses single nucleotide polymorphisms (SNPs) in a large cohort for beryllium-exposed persons. SNPs were chosen for their relevance in sarcoidosis. Even though one of largest cohorts of beryllium-exposed persons was analysed, no statistically relevant association between any SNP and CBD could be verified. Notably, some SNPs exhibit inverse OR for beryllium sensitization and CBD with nominally statistical significance, which allows hypothesizing about pathophysiological role of genes for the disease triggering and development.
\end{abstract}

Keywords: Sarcoidosis, Berylliosis chronic, Beryllium diesase, Genetic, Annexin A11, BTNL2

Chronic beryllium disease $(\mathrm{CBD})$ and sarcoidosis are granulomatous diseases similar in clinical presentation but different in their etiology [1]. Beryllium is the known trigger for CBD that elicits a type IV immune reaction with $\mathrm{CD} 4+$ (cluster of differentiation 4-positive) T-cell activation and proliferation (beryllium sensitization $(\mathrm{BeS})$ ). Beryllium sensitization (BeS) can be measured by the beryllium-specific lymphocyte proliferation test (BeLPT) allowing the differentiation between sarcoidosis and CBD [2]. A single SNP (single nucleotide polymorphism) in the HLA-DP (human leucocyte antigen of major histocompability complex II) represents a strong risk factor for disease development [3], but other genetic factors may contribute to beryllium sensitization and CBD. We hypothesized that SNPs described in sarcoidosis [4] may also be relevant for CBD and investigated SNPs from known sarcoidosis susceptibility loci

\footnotetext{
*Correspondence: joachim.mueller-quernheim@uniklinik-freiburg.de ${ }^{1}$ Department of Pneumology, Faculty of Medicine, Medical CenterUniversity of Freiburg, University of Freiburg, Killianstrasse 5, 79106 Freiburg, Germany Full list of author information is available at the end of the article Ainsley Weston: Retired.
}

(Interleukin 23 (IL23), butyrophilin-like 2 (BTNL2), ras-related protein 23 (rab23), Annexin A11 (ANXA11) and osteosarcoma 9 (OS9), in 1150 beryllium exposed, predominantly male individuals. These individuals were recruited from surveillance programs and outpatient clinics in US and Germany, including only individuals from Caucasian ancestry to reduce genetic heterogeneity. Beryllium exposure was assumed if the individual worked in a known beryllium-handling facility (thereby participating in surveillance programs) or a detailed occupational history revealed a workplace with a high susceptibility of beryllium exposure [2]. All participants had provided informed consent for their source studies. Within the studied cohort, 186 individuals had a confirmed abnormal BeLPT from peripheral blood and/or bronchoalveolar lavage. Of these individuals, thorough work-up including lung function, laboratory, radiological and histological investigations identified 93 individuals with granulomatous disease being classified as CBD individuals. In further 93 individuals no signs of granulomatous disease were found and they were considered as beryllium sensitized ( 93 individuals, $\mathrm{BeS}$ ). original author(s) and the source, provide a link to the Creative Commons licence, and indicate if changes were made. The images or other third party material in this article are included in the article's Creative Commons licence, unless indicated otherwise in a credit line to the material. If material is not included in the article's Creative Commons licence and your intended use is not permitted by statutory regulation or exceeds the permitted use, you will need to obtain permission directly from the copyright holder. To view a copy of this licence, visit http://creativecommons.org/licenses/by/4.0/. The Creative Commons Public Domain Dedication waiver (http://creativeco mmons.org/publicdomain/zero/1.0/) applies to the data made available in this article, unless otherwise stated in a credit line to the data. 


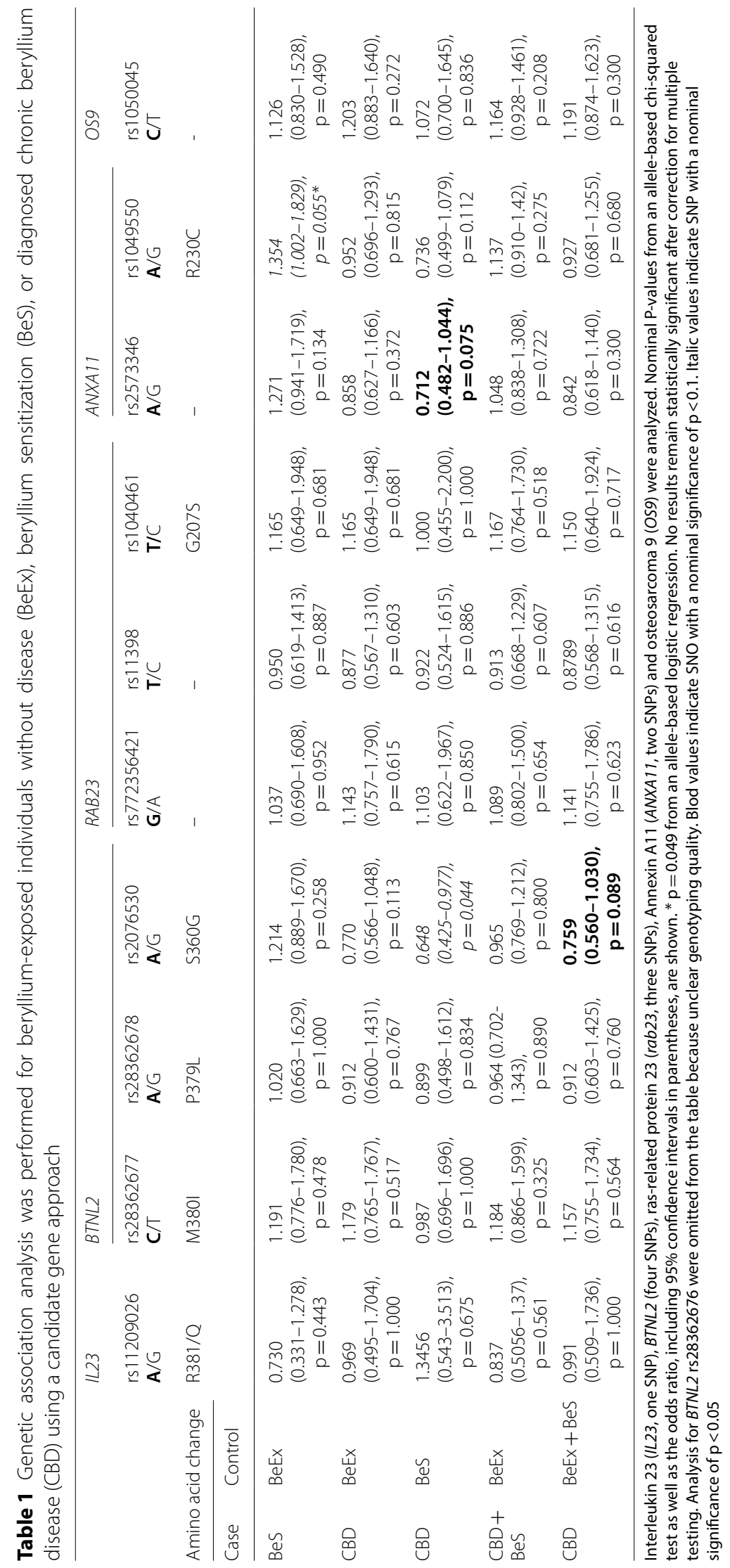


Eleven SNPs in five genes (Table 1 and BTNL2 rs28362676 [4], the latter one being of low genotyping quality requiring cautious interpretation) were genotyped as described previously [5]. Statistical analyses were performed in different combinations (Table 1, nominal p-values and ORs). Calculations of ORs, confidence intervals and allele-based statistical analysis of genotype data using a chi-squared test (CQT), with Yates correction where applicable, and logistic regression were carried out in R v3.6 [6].

None of the tested SNPs associated significantly with $\mathrm{BeS}$ or CBD after correction for multiple testing, most likely due to low numbers of BeS and CBD individuals. Misclassification of individuals to one group and genetic heterogeneity may be additional factors, even though cohort selection and experienced pneumological workup should reduce this risk.
Although potentially explained by chance, the nominally significant OR for BTNL-2 and ANXA11 may allow some detailed hypothesizing on the role of these genes in CBD development, especially considering the fact that CBD (in contrast to sarcoidosis) develops in individuals with a known trigger via an intermediate step of beryllium sensitization (Fig. 1).

ANXA11 SNPs (rs2573346, rs1049550) associate differentially as risk or protection factor for sarcoidosis [7] and the nominal p-values in our tests suggested a similar association of ANXA11 in CBD. SNP rs1049550 (A/G) was associated with BeS (OR 1.35, Table 1, bold square, $\mathrm{p}=0.055 ; \mathrm{p}=0.049$ in logistic regression test). Slight discrepancies of $\mathrm{CIs}$ and $\mathrm{p}$-values may result from imminent test conditions. SNP rs2573346 (A/G) showed borderline nominal significance for association with protection against $\mathrm{CBD}$ in $\mathrm{BeS}$ (OR 0.71, Table 1, dotted square). In summary, these results hint towards

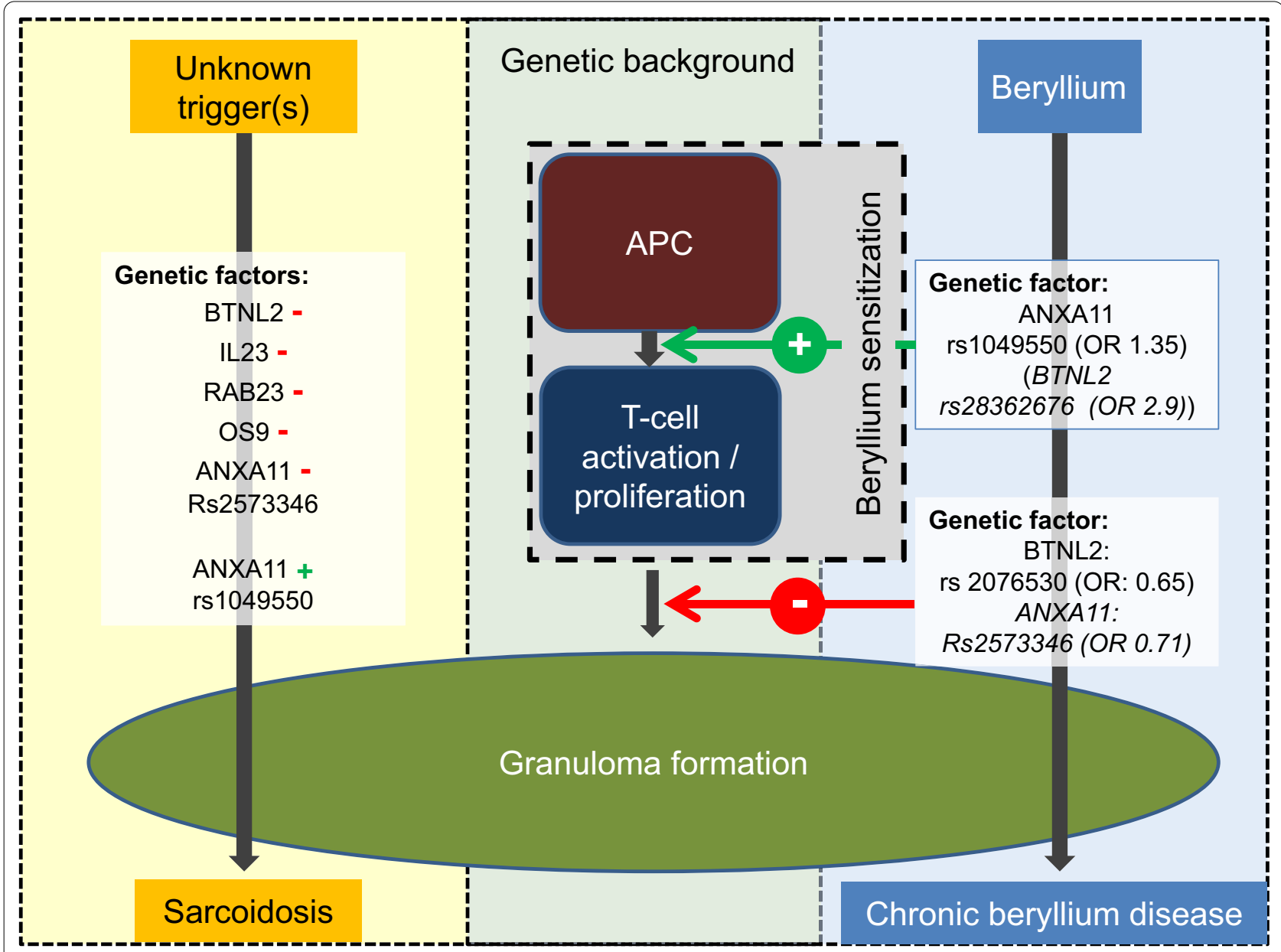

Fig. 1 Sarcoidosis and chronic beryllium disease (CBD) share granuloma formation and clinical phenotype as common hallmarks. Genetic studies propose specific SNPs (e.g. in the BTNL2 and ANXA11 genes) contributing to disease development. Red-indicating enhanced susceptibility and green + indicating protection in sarcoidosis. In CBD, these SNPs influence disease initiation and progression differentially, which has not been studied so far in sarcoidosis. (APC: antigen presenting cells) 
a role of ANXA in CBD, which may be comparable to the hypothesized function of ANXA 11. Interestingly, the effects might be linked to different steps during the development of CBD.

While BTNL-2 SNP rs2076530 (A/G) is a risk factor for sarcoidosis, it seems to protect individuals with BeS from developing CBD (OR 0.65 for CBD vs BeS, Table 1, bold square). Of note, this SNP has not been described for CBD, only the SNP rs3117099 within the BTNL-2 gene has been described to confer to CBD [8]. BTNL-2 SNP rs28362676 would have increased the risk of BeS (OR 2.9; data not shown), but low genotyping quality hindered its interpretation (therefore omitted from Table 1). Therefore this study could not demonstrate that BTNL2 SNPs were significantly associated with increased risk of $\mathrm{BeS}$, but it might reduce the risk of CBD which fits well with the hypothesized function of BTNL2 in granulomatous disease by limiting a T-cell response [9]. This would attribute a dual role to BTNL2 in disease initiation and progression (similar to annexin A11, Fig. 1).

Even though this study analyzed one of the largest CBD cohorts, the overall number of BeS and CBD individuals was low for a genetic study, which limits the statistical power and interpretability. Still a cohort with 3 times more CBD patients would only be sufficiently powered to obtain significant results for very common risk alleles, i.e. with frequencies $>0.25$, and with effect sizes stronger than those observed in our cohort, i.e. ORs $>2.0$ (GAS Power Calculator; https://csg.sph.umich.edu/abecasis/ gas_power_calculator/).

Despite this inherent limitation of genetic studies in rare diseases, these results allow hypothesizing on the pathogenic roles of some genes in granulomatous diseases. As depicted in Fig. 1, granuloma formation is the common final pathway of sarcoidosis and CBD. In difference to sarcoidosis, in CBD a unique initiating trigger is well defined and $\mathrm{BeS}$ is considered to be an intermediate step between beryllium exposure and CBD. The genetic analyses of BTNL-2 and ANXA 11 SNP point towards janiform roles of these genes in CBD with different effects on BeS and CBD. Different SNPs within these genes might associate with disease initiation or inversely with disease manifestation. As for sarcoidosis the intermediate step of T-cell activation without overt disease has not been characterized (Fig. 1), different genetic variants of BTNL2 and ANXA11 genes seem to contribute differentially to T-cell sensitization and progression to CBD in Be-exposed individuals (Fig. 1 and Table 1). This functional duality could also be true in sarcoidosis. However it has not been studied due to sarcoidosis heterogeneity, although similar findings have been described for some HLA haplotypes similar associations especially for
Löfgren's syndrome that associate with the risk of disease as well as with its resolution [4].

In summary, this genetic study didn't demonstrate statistically robust results despite one of the largest cohorts of beryllium-exposed individuals emphasizing the difficulties of genetic studies in rare disease. However, analyses of nominally significant OR for some SNP allow some more detailed hypothesis on the role of some genes relevant for granulomatous diseases.

\section{Abbreviations \\ ANXA 11: Annexin A11; APC: Antigen presenting cells; BeLPT: Beryllium-spe- cific lymphocyte proliferation test; BeS: Beryllium sensitization; BeEx: Beryllium exposure; BTNL2: Butyrophilin-like 2; CBD: Chronic beryllium disease; CD4+: Cluster of differentiation-4 positive, i.e. T-cells expressing cluster of differen- tiation-4; CQT: Chi-squared test; HLA: Human leukocyte antigen; HLA-DP: Human leukocyte antigen of the major histocompability complex II (MHC2); IL23: Interleukin-23; OR: Odd's ratio; OS9: Osteosarcoma-9; rab 23: Ras-related protein 23; SNP: Single nucleotide polymorphism; US: United States.}

\section{Disclaimer}

The findings and conclusions in this report are those of the authors and do not necessarily represent the official position of the National Institute for Occupational Safety and Health, Centers for Disease Control and Prevention.

\section{Authors' contributions}

BCF analysed the data and wrote the manuscript. KIG wrote the study protocol, managed aggregation of cohort, DNA samples, genotyping and clinical data, analysed the data and wrote the manuscript. CS conferred important DNA-samples and patient-related information. MDR conferred important DNA-samples and patient-related information. DSM conferred important DNA-samples and patient-related information. KDR conferred important DNA-samples and patient-related information. CRS conferred important DNA-samples and patient-related information and gave major input to the manuscript. AW conferred important DNA-samples and patient-related information. RW conferred important DNA-samples and patient-related information. RN performed genotyping and its quality control. GZ conferred DNA-samples, developed the study protocol, analyzed the data and wrote the manuscript. StSch performed genotyping and its quality control. MN analysed the data, calculated the statistics and gave major input to the manuscript. $J M Q$ developed the study protocol, and patient-related information, analyzed the data, wrote the manuscript and acquired funding. All authors read and approved the final manuscript.

\section{Funding}

This study was support by German Research Foundation (Mu692/7-1).

\section{Availability of data and materials}

Analyzed metadata can be obtained from Karoline I. Gaede on reasonable request in consideration of ethical and legal aspects. Source datasets are subject to the restrictions under which the data were collected and must be requested from the organizations that provided them for this study.

\section{Declarations}

\section{Ethics approval and consent for participation}

The main ethical approval was obtained by the Ethic Committee of the University of Freiburg, Germany, No. 80/04. All participants gave informed consent to data analyses including genetic analyses, when they agreed to the source studies.

\section{Consent for publication}

All participants gave informed consent to participate at the soruce studies. The manuscript does not contain any individual details of participants. 


\section{Competing interests}

$\mathrm{BCF}$ received speaker and consultant fees by Actelion, Boehringer Ingelheim, Novartis and Roche outside the submitted work. BCF acts as a consultant to and is shareholder of Advita Lifescience $\mathrm{GmbH}$. KIG indicates funding of the German Research Counsil (DFG) related to project. CS has nothing to disclose. MDR has nothing to disclose. DSM acts as a consultant to, receives royalities from and owns options of Omixon. KDR has nothing to disclose.CSR has nothing to disclose. AW has nothing to disclose. RW has nothing to disclose. RN has nothing to disclose. GZ has nothing to disclose. StSch has nothing to disclose. MN has nothing to disclose. JMQ reports personal fees from Novartis, personal fees from Roche, personal fees and other from Advita Lifescience $\mathrm{GmbH}$, outside the submitted work

\section{Author details}

${ }^{1}$ Department of Pneumology, Faculty of Medicine, Medical Center-University of Freiburg, University of Freiburg, Killianstrasse 5, 79106 Freiburg, Germany.

2 BioMaterial Bank Nord, Research Center Borstel, Leibniz Lung Center, 23845 Borstel, Parkallee 35, Germany. ${ }^{3}$ Department of Medicine, University of Florida, 1600 Archer Rd, Gainesville 32610, FL, USA. ${ }^{4}$ Pulmonary, Allergy, and Critical Care Division, University of Pennsylvania Medical Center, Philadelphia, USA. ${ }^{5}$ Division of Occupational and Environmental Medicine, Department of Medicine, Michigan State University, East Lansing, MI, USA. ${ }^{6}$ Centers for Disease Control and Prevention, National Institute for Occupational Safety and Health, Morgantown, WV, USA. ${ }^{7}$ Institute for Occupational and Maritime Medicine, University Medical Center Hamburg-Eppendorf, Hamburg, Germany. ${ }^{8}$ Institute for Clinical Molecular Biology, Christian-Albrechts University, Kiel, Germany. ${ }^{9}$ Department of Statistical Genetics and Bioinformatics, Cologne Center for Genomics (CCG), University of Cologne, Cologne, Germany. ${ }^{10}$ University Hospital Cologne, Cologne, Germany. ${ }^{11}$ Airway Research Center North, German Center for Lung Research (DZL), Wöhrendamm 80, 22927 Großhansdorf, Germany.

Received: 14 December 2020 Accepted: 22 March 2021 Published online: 16 April 2021

\section{References}

1. Mayer AS, Hamzeh N, Maier LA. Sarcoidosis and chronic beryllium disease: similarities and differences. Semin Respir Crit Care Med. 2014;35(3):316-29.

2. Balmes JR, Abraham JL, Dweik RA, Fireman E, Fontenot AP, Maier LA, et al. An official american thoracic society statement: diagnosis and management of beryllium sensitivity and chronic beryllium disease. Am J Respir Crit Care Med. 2014;190(10):e34-59.

3. Fontenot AP, Falta MT, Kappler JW, Dai S, McKee AS. Beryllium-induced hypersensitivity: genetic susceptibility and neoantigen generation. J Immunol. 2016;196(1):22-7.

4. Fischer A, Grunewald J, Spagnolo P, Nebel A, Schreiber S, MullerQuernheim J. Genetics of sarcoidosis. SeminRespir Crit Care Med. 2014:35(3):296-306.

5. Hofmann S, Franke A, Fischer A, Jacobs G, Nothnagel M, Gaede Kl, et al. Genome-wide association study identifies ANXA11 as a new susceptibility locus for sarcoidosis. Nat Genet. 2008;40(9):1103-6.

6. R Core Development Team. R: a language and environment for statistical computing. R Foundation for Statistical Computing, Vienna, Austria 2019.

7. Zhou H, Diao M, Zhang M. The association between ANXA11 gene polymorphisms and sarcoidosis: a meta-analysis and systematic review. Sarcoidosis Vasc Diffuse Lung Dis. 2016;33(2):102-11.

8. Sato H, Spagnolo P, Silveira L, Welsh Kl, du Bois RM, Newman LS, et al. BTNL2 allele associations with chronic beryllium disease in HLADPB1*Glu69-negative individuals. Tissue Antigens. 2007;70(6):480-6.

9. Broos CE, Hendriks RW, Kool M. T-cell immunology in sarcoidosis: Disruption of a delicate balance between helper and regulatory T-cells. CurrOpinPulm Med. 2016;22(5):476-83.

\section{Publisher's Note}

Springer Nature remains neutral with regard to jurisdictional claims in published maps and institutional affiliations.
Ready to submit your research? Choose BMC and benefit from:

- fast, convenient online submission

- thorough peer review by experienced researchers in your field

- rapid publication on acceptance

- support for research data, including large and complex data types

- gold Open Access which fosters wider collaboration and increased citations

- maximum visibility for your research: over $100 \mathrm{M}$ website views per year

At BMC, research is always in progress.

Learn more biomedcentral.com/submissions 